\title{
Insulin degludec/insulin aspart combination for the treatment of type I and type 2 diabetes
}

This article was published in the following Dove Press journal:

Vascular Health and Risk Management

5 August 2014

Number of times this article has been viewed

\author{
Angela Dardano \\ Cristina Bianchi \\ Stefano Del Prato \\ Roberto Miccoli \\ Department of Clinical and \\ Experimental Medicine, Section \\ of Diabetes and Metabolic \\ Diseases, University of Pisa, \\ Pisa, Italy
}

Correspondence: Angela Dardano Department of Clinical and Experimental Medicine, Section of Diabetes and Metabolic Diseases, University of Pisa, Via Paradisa 2, 56124, Pisa, Italy

Tel +39050995 109

Fax +39050 54I 52

Email angidardano@gmail.com
Abstract: Glycemic control remains the major therapeutic objective to prevent or delay the onset and progression of complications related to diabetes mellitus. Insulin therapy represents a cornerstone in the treatment of diabetes and has been used widely for achieving glycemic goals. Nevertheless, a large portion of the population with diabetes does not meet the internationally agreed glycemic targets. Moreover, insulin treatment, especially if intensive, may be associated with emergency room visits and hospitalization due to hypoglycemic events. Therefore, fear of hypoglycemia or hypoglycemic events represents the main barriers to the attainment of glycemic targets. The burden associated with multiple daily injections also remains a significant obstacle to initiating and maintaining insulin therapy. The most attractive insulin treatment approach should meet the patients' preference, rather than demanding patients to change or adapt their lifestyle. Insulin degludec/insulin aspart (IDegAsp) is a new combination, formulated with ultra-long-acting insulin degludec and rapid-acting insulin aspart, with peculiar pharmacological features, clinical efficacy, safety, and tolerability. IDegAsp provides similar, noninferior glycemic control to a standard basal-bolus regimen in patients with type 1 diabetes mellitus, with additional benefits of significantly lower episodes of hypoglycemia (particularly nocturnal) and fewer daily insulin injections. Moreover, although treatment strategy and patients' viewpoint are different in type 1 and type 2 diabetes, trial results suggest that IDegAsp may be an appropriate and reasonable option for initiating insulin therapy in patients with type 2 diabetes inadequately controlled on maximal doses of conventional oral agents. This paper will discuss the role of IDegAsp combination as a novel treatment option in diabetic patients.

Keywords: diabetes mellitus, insulin analogs, insulin degludec/insulin aspart, IDegAsp, hypoglycemia

\section{Introduction}

Diabetes mellitus (DM) has become a widespread epidemic, and the number of people with diabetes will more than double over the next years, due to population growth and aging. ${ }^{1}$ Good glycemic control remains the basis of managing diabetes and plays a key role in preventing or delaying the onset and progression of diabetic complications in both patients with type 1 or type 2 DM. The American Diabetes Association and the European Association for the Study of Diabetes have released statements on glycemic goals, advocating the early use of insulin. ${ }^{2}$ Insulin therapy represents a cornerstone in the treatment of all patients with type $1 \mathrm{DM}$, and it is indicated in most patients with type 2 DM. Prospective randomized clinical trials have demonstrated that improved glycemic control is associated with sustained decreased rates of microvascular complications. ${ }^{3-6}$ 
Recent publications continue to underline the essential role of good glycemic control in reducing the risk of diabetes complications. ${ }^{7}$ On the other hand, whether good glycemic control has any impact on reducing macrovascular complications is still a matter of debate. When all the large, long-term, prospective randomized controlled clinical trials (such as the United Kingdom Prospective Diabetes Study [UKPDS], the prospective pioglitazone clinical trial in macrovascular events [PROactive], the Action in Diabetes and Vascular Disease: Preterax and Diamicron MR Controlled Evaluation [ADVANCE] trial, the Veterans Affairs Diabetes Trial [VADT] and the Action to Control Cardiovascular Risk in Diabetes [ACCORD] trial) are included in a metaanalysis, glycemic control resulted in a $17 \%$ reduction in events of nonfatal myocardial infarction (odds ratio [OR], 0.83 ; $95 \%$ confidence interval $[\mathrm{CI}] 0.75-0.93$ ), and a $15 \%$ reduction in events of coronary heart disease (OR, 0.85; 95\% CI 0.77-0.93). ${ }^{8}$

However, the effect on cardiovascular death varied among studies, with the evidence of statistical heterogeneity. Compared with standard therapy, intensive therapy increased the risk of cardiovascular death in the ACCORD trial and had a neutral or salutary effect in the ADVANCE and the UKPDS trials. ${ }^{9}$ Despite better microvascular outcomes, intensive insulin therapy has been associated with a high rate of severe hypoglycemia. ${ }^{3,10}$

Similarly, the rates of major hypoglycemic episodes per year were higher in insulin-treated type 2 diabetes as compared to conventional treatments: $0.7 \%$ with conventional treatment; $1.0 \%$ with chlorpropamide; $1.4 \%$ with glibenclamide; and $1.8 \%$ with insulin. ${ }^{4}$ The higher risk of hypoglycemia with intensive treatment has been confirmed also in the major clinical trials (VADT, ADVANCE, ACCORD, and PROactive).${ }^{11}$ Moreover, results of the posthoc analyses of both the ACCORD and VADT trials have shown a strong association between severe hypoglycemia and cardiovascular mortality. ${ }^{12}$ In a very recent large prospective cohort of type $2 \mathrm{DM}$, severe hypoglycemia has been also associated with high rates of death. ${ }^{13}$ Moreover, hypoglycemia has been related to recurrent morbidity, increased risk of emergency room visits, and hospitalization. ${ }^{14}$

\section{New opportunities in clinical management of diabetes}

Fear of hypoglycemia and hypoglycemia events has a large impact on patients' lives and quality-of-life, and continues to be a major problem for diabetic people. ${ }^{15-18}$ The main obstacles to optimizing insulin therapy also include the burden associated with multiple daily injections. ${ }^{19}$ To overcome these barriers, a simpler insulin regimen with fewer daily injections could offer a greater degree of flexibility in dosing time, thus improving treatment adherence. The goal for insulin therapy is to mimic the physiological pattern of insulin secretion seen in nondiabetic patients, and the success of insulin therapy ultimately depends on how closely a given regimen can mimic the normal physiology. ${ }^{20,21}$ In this perspective, the introduction of the so-called designer insulins - the insulin analogs - has offered new opportunities in the clinical management of diabetes. ${ }^{22,23}$

Insulin analogs (the short-acting insulin analogs: lispro, aspart, and glulisine and the long-acting insulin analogs: detemir and glargine) have been shown in many instances to be associated with reduced risks of hypoglycemia, lower levels of postprandial glucose excursions, better patient adherence, greater quality of life, and higher satisfaction with treatment in both type 1 and type 2 diabetic patients, as compared to traditional insulins. ${ }^{24-29}$

However, in terms of pharmacokinetics and pharmacodynamics, currently available insulin analogs still have some limitations, failing to reproducibly provide insulin coverage over a full 24 hours and to do so from day to day. ${ }^{30,31}$ Therefore, improvements are desirable, particularly in the area of long-acting insulin analogs, where effective oncedaily clinical use might not be possible in all patients and may require patients to administer insulin at a specific time of day, which may not always be convenient or remembered. ${ }^{30}$

Indeed, the first generation of basal analogs like glargine (IGlar) and detemir (IDet) has certain shortcomings that do not allow them to be termed ideal basal insulins. IGlar is said to be peakless, but it may be associated with interindividual variability. Many patients exhibit peaks in action, especially at higher doses, while IDet, which is a peakless, stable insulin, may need to be injected twice daily in type 1 diabetes and when given in smaller doses. ${ }^{32}$

Insulin degludec (IDeg) is a neutral ultra-long-acting new generation basal insulin analog that was developed by Novo Nordisk (Bagsvaerd, Denmark) and recently approved in the European Union for use as basal insulin therapy in patients with type 1 and type $2 \mathrm{DM} \cdot{ }^{33}$ IDeg has been designed to have a longer half-life and lower pharmacodynamic variability than currently available basal insulin products. ${ }^{34-38}$ The efficacy and safety of IDeg in the treatment of diabetic patients have been evaluated in type 1 and 2 diabetes (Table 1). Pharmacokinetic and pharmacodynamics data demonstrated that its mechanism of protraction results in an ultralong duration of action with a flat steady-state plasma profile. Clinical 
Table I Summary of main studies using IDeg in patients with type I and type 2 DM

\begin{tabular}{|c|c|c|c|}
\hline Authors & Study design & Comparators & Type of patients \\
\hline $\begin{array}{l}\text { Birkeland } \mathrm{KI} \text { et al }{ }^{40} \\
\text { Diabetes Care, 20I I }\end{array}$ & $\begin{array}{l}\text { I6-week, randomized, controlled, } \\
\text { open-label, three-arm, parallel group trial }\end{array}$ & $\begin{array}{l}\text { IDeg (600 micromol/L); IDeg } \\
\text { (900 micromol/L) versus IGlar }\end{array}$ & Type I DM \\
\hline $\begin{array}{l}\text { Heller S et } \mathrm{al}^{41} \\
\text { Lancet, } 2012\end{array}$ & $\begin{array}{l}\text { Open-label, treat-to-target, noninferiority } \\
\text { trial }\end{array}$ & IDeg versus IGlar & Type I DM \\
\hline $\begin{array}{l}\text { Heise } T \text { et } \mathrm{a}^{35} \\
\text { Diabetes Obes Metab, } \\
2012\end{array}$ & $\begin{array}{l}\text { Randomized, single-center, parallel-group, } \\
\text { double-blind trial }\end{array}$ & IDeg versus IGlar & Type I DM \\
\hline $\begin{array}{l}\text { Mathieu C et al }{ }^{42} \\
\text { J Clin Endocrinol } \\
\text { Metab, } 2013\end{array}$ & $\begin{array}{l}26+26-\text {-week, randomized, controlled, } \\
\text { open-label, multinational, parallel-design, } \\
\text { treat-to-target, noninferiority trial }\end{array}$ & $\begin{array}{l}\text { IDeg (once daily, varying injection } \\
\text { timing day) versus IGlar }\end{array}$ & Type I DM \\
\hline $\begin{array}{l}\text { Bode BW et al }{ }^{43} \\
\text { Diabet Med, } 2013\end{array}$ & $\begin{array}{l}\text { Open-label trial ( } 1 \text {-year main trial }+ \text { I-year } \\
\text { extension trial) }\end{array}$ & IDeg versus IGlar & Type I DM \\
\hline $\begin{array}{l}\text { Koehler G et al }{ }^{44} \\
\text { Diabetologia, } 2014\end{array}$ & $\begin{array}{l}\text { Double-blind, randomized, two-period, } \\
\text { crossover trial }\end{array}$ & IDeg versus IGlar & Type I DM \\
\hline $\begin{array}{l}\text { Korsatko S et a }{ }^{45} \\
\text { Drugs Aging, } 2014\end{array}$ & $\begin{array}{l}\text { Single-center, randomized, multiple-dose, } \\
\text { double-blind, two-period, crossover trial }\end{array}$ & $\begin{array}{l}\text { IDeg (pharmacokinetics/ } \\
\text { pharmacodynamics) }\end{array}$ & $\begin{array}{l}\text { Type I DM (including elderly } \\
\text { patients) }\end{array}$ \\
\hline $\begin{array}{l}\text { Biester T et a }{ }^{46} \\
\text { Pediatr Diabetes, } 2014\end{array}$ & $\begin{array}{l}\text { Single center, randomized, single dose, } \\
\text { double-blind two-period, crossover trial }\end{array}$ & IDeg versus IGlar & $\begin{array}{l}\text { Type I DM (children, } \\
\text { adolescents, and adults) }\end{array}$ \\
\hline $\begin{array}{l}\text { Davies MJ et a }{ }^{47} \\
\text { Diabetes Obes Metab, } \\
2014\end{array}$ & $\begin{array}{l}\text { Multinational, 26-week, controlled, } \\
\text { open-label, parallel group randomized trial }\end{array}$ & IDeg versus IDet & Type I DM \\
\hline $\begin{array}{l}\text { Zinman B et al }\left.\right|^{48} \\
\text { Lancet, 20II }\end{array}$ & $\begin{array}{l}\text { I6-week, randomized, open-label, parallel } \\
\text { group, Phase II trial }\end{array}$ & IDeg versus IGlar & Type 2 DM \\
\hline $\begin{array}{l}\text { Garber AJ et a }{ }^{49} \\
\text { Lancet, } 2012\end{array}$ & $\begin{array}{l}\text { 52-week, Phase III, open-label, treat-to- } \\
\text { target, noninferiority trial }\end{array}$ & IDeg versus IGlar & Type 2 DM \\
\hline $\begin{array}{l}\text { Heise } \mathrm{T} \text { et } \mathrm{al}^{50} \\
\text { Diabetes Obes Metab, } \\
2012\end{array}$ & $\begin{array}{l}\text { Randomized, single center, double-blind, } \\
\text { two-period, incomplete block crossover, } \\
\text { multiple dose trial }\end{array}$ & $\begin{array}{l}\text { IDeg } 100 \mathrm{U} / \mathrm{mL} \\
(0.4 \mathrm{U} / \mathrm{kg} ; 0.6 \mathrm{U} / \mathrm{kg}, 0.8 \mathrm{U} / \mathrm{kg}) \\
\text { IDeg } 200 \mathrm{U} / \mathrm{mL} \\
(0.6 \mathrm{U} / \mathrm{Kg}) \text { (pharmacokinetics) }\end{array}$ & Type 2 DM \\
\hline $\begin{array}{l}\text { Zinman B et al }{ }^{51} \\
\text { Diabetes Care, } 2012\end{array}$ & $\begin{array}{l}\text { 52-week, randomized, controlled, I year, } \\
\text { parallel group, open-label, multinational, } \\
\text { treat-to-target, noninferiority trial }\end{array}$ & IDeg versus IGlar & Type 2 DM \\
\hline $\begin{array}{l}\text { Meneghini L et al }{ }^{52} \\
\text { Diabetes Care, } 2013\end{array}$ & $\begin{array}{l}\text { Phase III, } 26 \text {-week, randomized, controlled, } \\
\text { open-label, three-arm, parallel group trial }\end{array}$ & $\begin{array}{l}\text { Once-daily IDeg, in a prespecified } \\
\text { dosing schedule; once-daily IDeg, } \\
\text { at the main evening meal; once- } \\
\text { daily IGlar, at the same time } \\
\text { each day }\end{array}$ & Type 2 DM \\
\hline $\begin{array}{l}\text { Philis-Tsimikas A et } \mathrm{al}^{53} \\
\text { Diabetes Obes Metab, } \\
2013\end{array}$ & $\begin{array}{l}\text { 26-week, randomized, open-label, } \\
\text { multicenter, multinational, controlled trial }\end{array}$ & IDeg versus sitagliptin & Type 2 DM \\
\hline $\begin{array}{l}\text { Gough SC et al }{ }^{54} \\
\text { Diabetes Care, } 2013\end{array}$ & 26-week, open-label, treat-to-target trial & IDeg versus IGlar & Type 2 DM \\
\hline $\begin{array}{l}\text { Philis-Tsimikas A et al }{ }^{55} \\
\text { Adv Ther, } 2013\end{array}$ & $\begin{array}{l}\text { 26-week, multinational, Phase IIlb, multicenter, } \\
\text { two-armed, parallel group, open-label, } \\
\text { randomized, treat-to-target trial }\end{array}$ & $\begin{array}{l}\text { IDeg simple algorithm versus } \\
\text { IDeg stepwise algorithm }\end{array}$ & Type 2 DM \\
\hline $\begin{array}{l}\text { Rodbard HW et al }{ }^{56} \\
\text { Diabet Med, } 2013\end{array}$ & $\begin{array}{l}\text { Randomized, controlled, parallel group, } \\
\text { open-label, multinational, treat-to-target, } \\
\text { noninferiority trial }\end{array}$ & IDeg versus IGlar & Type 2 DM \\
\hline $\begin{array}{l}\text { Zinman B et a }{ }^{57} \\
\text { Lancet Diabetes } \\
\text { Endocrinol, } 2013\end{array}$ & $\begin{array}{l}\text { Two Phase III, 26-week, randomized, } \\
\text { open-label, treat-to-target, noninferiority } \\
\text { trials }\end{array}$ & $\begin{array}{l}\text { IDeg injected three times a week } \\
\text { versus IGlar once daily }\end{array}$ & Type 2 DM \\
\hline $\begin{array}{l}\text { Kiss I et } \mathrm{al}^{58} \\
\text { Clin Pharmacokinet, } \\
2014\end{array}$ & $\begin{array}{l}\text { Single center, single dose, open-label, } \\
\text { parallel group trial }\end{array}$ & IDeg (pharmacokinetics) & $\begin{array}{l}\text { Patients with normal or } \\
\text { impaired renal function } \\
\text { (I I/30 with Type } 2 \text { DM) }\end{array}$ \\
\hline $\begin{array}{l}\text { Kupčová } \vee \text { et al }{ }^{59} \\
\text { Clin Drug Investig, } 2014\end{array}$ & $\begin{array}{l}\text { Single center, single dose, open-label, } \\
\text { parallel group trial }\end{array}$ & IDeg (pharmacokinetics) & $\begin{array}{l}\text { Patients with hepatic impairment } \\
\text { (Child-Pugh grade A, B, or C) } \\
\text { ( } 3 / 24 \text { with Type } 2 \text { DM) }\end{array}$ \\
\hline
\end{tabular}

(Continued) 
Table I (Continued)

\begin{tabular}{|c|c|c|c|}
\hline Authors & Study design & Comparators & Type of patients \\
\hline $\begin{array}{l}\text { Mathieu C et al }{ }^{60} \\
\text { Diabetes Obes Metab, } \\
2014\end{array}$ & $\begin{array}{l}\text { Multinational, Phase IIlb, open-label, } \\
\text { randomized, treat-to-target trial (52-week } \\
\text { main trial BEGIN ONCE-Long + 52-week } \\
\text { extension) }\end{array}$ & $\begin{array}{l}\text { IDeg + liraglutide versus IDeg + } \\
\text { IAsp }\end{array}$ & Type 2 DM \\
\hline $\begin{array}{l}\text { Rodbard HW et } \mathrm{al}^{61} \\
\text { Diabetes Obes Metab, } \\
2014\end{array}$ & 52 week open-label, treat-to-target trial & IDeg versus IGlar & Type 2 DM \\
\hline $\begin{array}{l}\text { Hompesch } M \text { et al }{ }^{62} \\
\text { Clin Ther, } 2014\end{array}$ & $\begin{array}{l}\text { Randomized, single center, double-blind, two } \\
\text { period crossover trial }\end{array}$ & IDeg versus IDet & $\begin{array}{l}\text { Type } 2 \text { DM (African American, } \\
\text { Hispanic/Latino, White) }\end{array}$ \\
\hline $\begin{array}{l}\text { Bode BW et al }{ }^{63} \\
\text { Endocr Pract, } 2014\end{array}$ & 22-week, treat-to-target trial & $\begin{array}{l}\text { IDeg }(200 \mathrm{U} / \mathrm{mL}) \text { versus IDeg } \\
(100 \mathrm{U} / \mathrm{mL})\end{array}$ & Type 2 DM \\
\hline
\end{tabular}

Abbreviations: IDeg, insulin degludec; IGlar, insulin glargine; IDet, insulin detemir; type I DM, type I diabetes mellitus; type 2 DM, type 2 diabetes mellitus; IAsp, insulin aspart.

studies have shown that these characteristics may translate into the achievement of glycemic control with a lower risk of hypoglycemia, especially at night. ${ }^{39}$

A summary of the main studies using IDeg in patients with type 1 and type 2 DM is reported in Table 1.

Another unique pharmacological property of IDeg is that it can be coformulated with insulin aspart (IAsp), resulting, for the first time, in a soluble preparation comprising two different insulin analogs: 70\% of basal analog IDeg and $30 \%$ short-acting analog IAsp (IDegAsp). ${ }^{64}$ By providing both basal and rapid-acting insulin analogs in one injection, IDegAsp marks an important innovation in insulin therapy and could represent a novel area for therapeutic intervention in diabetes.

\section{IDeg/IAsp: notes on chemistry, pharmacokinetics, and pharmacodynamics}

IDeg is a long-acting basal insulin modified such that the amino acid residue threonine in position B30 (ThrB30) of human insulin has been omitted and the $\varepsilon$-amino group of lysine in position B29 (LysB29) has been coupled to hexadecanedioic acid via a spacer of glutamic acid. The structural formula is
Lys ${ }^{\mathrm{B} 29} \mathrm{~N}^{\varepsilon}$-hexadecanoyl- $\gamma$-L-Glu desB30 human insulin with a molecular formula of $\mathrm{C}_{274} \mathrm{H}_{411} \mathrm{~N}_{65} \mathrm{O}_{81} \mathrm{~S}$, giving a theoretical average molecular weight of 6,104.1 Da (Table 2). ${ }^{34,37}$

This structure allows IDeg to form soluble and stable multihexamers, resulting in a depot in the subcutaneous tissue after the injection. The gradual separation of IDeg monomers from the multihexamers results in a slow and continuous delivery of IDeg from the subcutaneous injection site into the circulation, leading to flat and stable pharmacokinetic and pharmacodynamic profiles. The mean terminal half-life of insulin degludec exceeds 25 hours in patients with either type 1 or type 2 diabetes, with a duration of action exceeding 42 hours in most patients. ${ }^{34-38}$

IAsp is a modified analog of human insulin where the amino acid proline has been replaced with aspartic acid at position 28. The molecular formula of IAsp is $\mathrm{C}_{256} \mathrm{H}_{381} \mathrm{~N}_{65} \mathrm{O}_{79} \mathrm{~S}$, and it has a molecular mass of 5,825.8 Da (Table 2) ${ }^{65}$ With a single amino acid change, the strength of binding between the monomers has been made weak; therefore, IAsp immediately dissociates into small, single monomers that are rapidly absorbed into the blood circulation. ${ }^{66-68}$ The pharmacokinetic profile for IAsp has been well-established, ${ }^{68}$ and its use across the spectrum of diabetic

Table 2 Chemical structure and pharmacokinetic/pharmacodynamic profiles of IAsp, IGlar, IDet, and IDeg

\begin{tabular}{|c|c|c|c|c|}
\hline & IAsp & IGlar & IDet & IDeg \\
\hline $\begin{array}{l}\text { Molecular formula } \\
\text { Molecular weight }\end{array}$ & $\begin{array}{l}\mathrm{C}_{256} \mathrm{H}_{381} \mathrm{~N}_{65} \mathrm{O}_{79} \mathrm{~S}_{6} \\
5,825.8 \mathrm{Da}\end{array}$ & $\begin{array}{l}\mathrm{C}_{267} \mathrm{H}_{404} \mathrm{~N}_{72} \mathrm{O}_{78} \mathrm{~S}_{6} \\
6,063.0 \mathrm{Da}\end{array}$ & $\begin{array}{l}\mathrm{C}_{267} \mathrm{H}_{402} \mathrm{O}_{76} \mathrm{~N}_{64} \mathrm{~S}_{6} \\
5,916.9 \mathrm{Da}\end{array}$ & $\begin{array}{l}\mathrm{C}_{274} \mathrm{H}_{411} \mathrm{~N}_{65} \mathrm{O}_{81} \mathrm{~S}_{6} \\
6,103.97 \mathrm{Da}\end{array}$ \\
\hline Formulation properties & Rapid-acting analog & $\begin{array}{l}\text { Formation of microprecipitates, } \\
\text { or stabilized aggregates; slow } \\
\text { dissolution of free hexamers }\end{array}$ & $\begin{array}{l}\text { Dihexamerization and } \\
\text { albumin binding }\end{array}$ & $\begin{array}{l}\text { Multihexamer } \\
\text { formation }\end{array}$ \\
\hline Onset & 15 minutes & $30-60$ minutes & $30-60$ minutes & 30-90 minutes \\
\hline Peak & I-3 hours & Relatively flat & Relatively flat & Flat \\
\hline Duration & $3-5$ hours & 24 hours & Up to 24 hours & $>24$ hours \\
\hline Dosing & Premeal & Same time every day & $\begin{array}{l}\text { Same time every day (once- } \\
\text { daily or twice-daily) }\end{array}$ & Any time of day \\
\hline
\end{tabular}

Abbreviations: IAsp, insulin aspart; IGlar, insulin glargine; IDet, insulin detemir; IDeg, insulin degludec; Da, dalton. 
patients has been recently reviewed. ${ }^{69,70}$ Strong evidence has suggested that IAsp is suitable in different settings, such as emergency departments and intensive/nonintensive care units, as well as in patients aged $\geq 65$ years. $^{70}$

A very novel and peculiar feature of IDeg, which is not shared by IGlar or IDet, is the possibility of being combined with rapid-acting IAsp..$^{71}$ IGlar has been formulated with an amino acid substitution at position A21 (asparagine replaced by glycine) and two arginines at the $\mathrm{C}$-terminus of the $\mathrm{B}$-chain (B31 and B32). These changes shift the isoelectric point from 5.4-6.7, which make the agent most soluble at a slightly acidic $\mathrm{pH}(\mathrm{pH} 4)$ and less soluble under neutral conditions. ${ }^{72}$ Conversely, rapid-acting insulin analogs are prepared in neutral formulations, becoming unstable at a slightly acidic pH. ${ }^{72}$ IDet, which has been modified from the human insulin structure through the addition of a $\mathrm{C} 14$ fatty acid side chain at position $\mathrm{B} 29$, is soluble in a neutral $\mathrm{pH}$ formulation, ${ }^{72}$ but its self-associated structures are less stable than the dihexamers of IDeg and could form, when mixed in the same formulation as a rapid-acting analogs, hybrid hexamers with unpredictable pharmacodynamics and pharmacokinetics. ${ }^{34}$ Therefore, currently existing basal insulin analogs (IGlar and IDet) are not available as combination formulations with fast-acting insulin analogs. ${ }^{34}$

Insulin degludec/insulin aspart (IDegAsp) is the first soluble combination of two different insulin analogs $(70 \%$ IDeg, as basal insulin; 30\% IAsp, as prandial insulin), providing basal insulin coverage and a prandial insulin bolus in a single injection. ${ }^{34}$ The molecular structure of IDeg allows it to be coformulated with IAsp in the presence of zinc and phenol, without the risk of hybrid hexamers formation, ${ }^{34}$ giving rise to an absorption profile of IDegAsp that resembles that of IDeg and IAsp when injected separately. In solution, the two insulin components exist in soluble and stable forms - IDeg as dihexamers and IAsp as hexamers, respectively. ${ }^{34,73}$ IDegAsp is able to provide a pharmacokinetic/pharmacodynamic profile with a clear distinction between the effects of the basal (IDeg) and rapid (IAsp) components. ${ }^{38}$

Table 2 summarizes the chemical structures and pharmacokinetic/pharmacodynamic profiles of IDeg, IGlar, IDet, and IAsp.

\section{IDegAsp: overview of clinical pharmacology trials Type I diabetes}

The efficacy and tolerability of IDegAsp, the new insulin coformulation, has been evaluated in a randomized, openlabel, multicenter, 26-week, Phase III, treat-to-target trial that included patients ( $\mathrm{n}=548)$ affected by type 1 diabetes for at least 12 months (glycated hemoglobin $\left[\mathrm{HbA}_{1 \mathrm{c}}\right] 7.0 \%-10.0 \%$, inclusive), randomized 2:1 to IDegAsp or IDet. ${ }^{20}$

In the first group of treatment, IDegAsp was given oncedaily plus mealtime IAsp for remaining meals. In the second group, IDet was administered in the evening and IAsp at all meals with a second dose of IDet added at breakfast in the case of inadequate glycemic control after 8 weeks. The IDegAsp and IDet doses were adjusted to a prebreakfast plasma glucose (PG) target of 4-5 mmol/L (72-90 mg/dL); whereas, morning doses of IDet were titrated based on the mean predinner PG levels, again aiming for $4-5 \mathrm{mmol} / \mathrm{L}$. Changes were made on the basis of mean self-measured PG value from the preceding 3 days.

The primary endpoint was the change from baseline in $\mathrm{HbA}_{1 \mathrm{c}}$ after 26 weeks of treatment. Secondary endpoints included, among others, the percentage of patients reaching $\mathrm{HbA}_{1 \mathrm{c}}<7.0 \%$ and the change from baseline in fasting PG (FPG). Safety assessments comprised adverse events, hypoglycemic events, insulin doses (total insulin dose and basal and bolus doses), body weight, laboratory tests, and vital signs. After 26 weeks of treatment, $\mathrm{HbA}_{1 \mathrm{c}}$ decreased over 26 weeks in both treatment strategy groups to $7.6 \%$. The mean change from baseline to week 26 was $-0.75 \%$ with IDegAsp and $-0.70 \%$ with IDet. The estimated treatment difference (ETD) of IDegAsp versus IDet was $-0.05 \%$ (95\% $\mathrm{CI}-0.18$ to 0.08 ), confirming the noninferiority of IDegAsp relative to IDet.

Moreover, there was no significant difference in the proportion of patients achieving the $\mathrm{HbA}_{1 \mathrm{c}}$ target of $<7.0 \%$ at week 26 (24.6\% with IDegAsp and 20.3\% with IDet; $P=$ not significant $[\mathrm{NS}])$. The observed mean FPG was $8.7 \mathrm{mmol} / \mathrm{L}(157 \mathrm{mg} / \mathrm{dL})$ for IDegAsp and $8.6 \mathrm{mmol} / \mathrm{L}$ $(155 \mathrm{mg} / \mathrm{dL})$ for IDet. The ETD of IDegAsp versus IDet was 0.23 ( -0.46 to 0.91$) \mathrm{mmol} / \mathrm{L}$, NS; $\sim 4.1$ (-8.3 to 16.4$)$ $\mathrm{mg} / \mathrm{dL}$. At the end of the study, the total insulin dose was $13 \%$ lower in the IDegAsp group (69 units [0.86 units/kg]; basal, 29 units [0.37 units $/ \mathrm{kg}$ ]; bolus, 39 units [0.49 units $/ \mathrm{kg}]$ ) than in the IDet group (79 units [1.00 units/kg]; basal, 36 units [0.46 units/ $/ \mathrm{kg}]$; bolus, 43 units [0.54 units $/ \mathrm{kg}])$. The ETD was 0.87 units ([0.82-0.92]; $P<0.0001)$, while the bolus insulin dose was not significantly different between treatment groups.

In addition, although the observed rates of overall confirmed hypoglycemia were not different between the groups, the rate of nocturnal confirmed hypoglycemia was significantly lower in the IDegAsp group as compared with the IDet-treated group, corresponding to a $37 \%$ lower rate, with 
3.71 versus 5.72 episodes/patient year (rate ratio [RR], 0.63; 95\% CI [0.49-0.81]; $P<0.0003)$. At week 26, the observed mean weight gain was $1 \mathrm{~kg}>$ with IDegAsp $(2.3 \mathrm{~kg})$ than with IDet $(1.3 \mathrm{~kg})$. The ETD of IDegAsp versus IDet was 1.04 (0.38-1.69); $P<0.0021$.

No differences were observed in the other secondary endpoints, such as laboratory measurements, physical examination, vital signs, electrocardiograms, or fundoscopy. Overall rates of treatment emergent adverse events were similar between the two treatment arms. As the health-related quality of life is a significant part of diabetes management, Hirsch et $\mathrm{al}^{20}$ have taken into account the impact of IDegAsp on this area of care. At the end of the trial, there were no significant differences between the treatment groups in all scores and domains evaluated; thus, the IDegAsp was well-tolerated without negative impacts on the quality of life.

In summary, the IDegAsp effectively improved glycemic control, being noninferior to IDet in basal-bolus therapy in patients with type 1 diabetes, while the total insulin dose and the nocturnal confirmed hypoglycemia were all lower as compared to IDet + IAsp. Therefore, although the superiority of the new insulin combination is not supported, these data suggest that IDegAsp may provide another opportunity particularly for those with a limitation in handling classic multiple-dose insulin therapy with the advantage of reduced risk of nocturnal hypoglycemia.

\section{Type 2 diabetes}

The efficacy of IDegAsp in insulin-naïve patients with type 2 diabetes has been evaluated in two randomized, open-label, multicenter, Phase II trials, in which the new formulation IDegAsp has been compared with two other different insulin analogs - IGlar or biphasic IAsp. ${ }^{74,75}$ The first 16-week, open-label, treat-to-target trial has compared IDegAsp with IGlar in diabetic patients inadequately controlled with oral antidiabetic drugs. ${ }^{74}$ Subjects were randomized to oncedaily IDegAsp, in two different formulations (IDeg 70\% and IAsp 30\% or IDeg 55\% and IAsp 45\%) or IGlar - all in combination with metformin. However, for the purpose of this review, only the first one will be considered. In the study by Heise, ${ }^{74}$ insulin was given before dinner and individually titrated based on a target fasting plasma glucose (FPG) of 4.0-6.0 $\mathrm{mmol} / \mathrm{L}$.

The primary endpoint was change in $\mathrm{HbA}_{1 \mathrm{c}}(\%)$ after 16 weeks of treatment. Over the course of the 16-week trial, mean $\mathrm{HbA}_{1 \mathrm{c}}$ decreased in all groups to comparable levels (IDegAsp, 7.0\%; IGlar, 7.1\%). A similar proportion of patients reached end-of-trial $\mathrm{HbA}_{1 \mathrm{c}}$ targets of $<7.0 \%$, without confirmed hypoglycemia in the last 4 weeks of treatment (IDegAsp, 51\%; IGlar, 50\%). The mean increase in 2-hour postdinner was significantly lower with IDegAsp $(0.13 \mathrm{mmol} / \mathrm{L})$ as compared with IGlar $(1.63 \mathrm{mmol} / \mathrm{L})$; whereas, mean FPG was similar (IDegAsp, $6.8 \mathrm{mmol} / \mathrm{L}$; IGlar, $7.0 \mathrm{mmol} / \mathrm{L})$. Hypoglycemia rates were low for both IDegAsp and IGlar (1.2 and 0.7 events/patient year, respectively), and nocturnal confirmed hypoglycemic events occurred rarely and in the same way (IDegAsp, one event; IGlar, three events). At end-of-trial, the mean daily insulin doses were $\sim 20 \%$ lower for IDegAsp than IGlar $(0.38 \pm 0.16$ and $0.45 \pm 0.20$ units $/ \mathrm{kg}$, respectively). In conclusion, in this trial, once-daily IDegAsp was safe and provided similar overall glycemic control to IGlar, with lower doses of insulin and better control of postdinner glucose, without incurring a higher risk for nocturnal hypoglycemia.

The authors also conducted a secondary analysis in a subset of type 2 diabetic patients that has been recently published..$^{76}$ A total of 112 type 2 diabetic patients, treated with metformin, underwent continuous interstitial glucose (IG) monitoring for 72 hours, after 16 weeks of treatment with IDegAsp or IGlar, given before the evening meal. ${ }^{76}$ The IDegAsp treatment was associated with flatter and more stable nightly glucose profiles than those observed with IGlar. The observed mean fluctuation in nocturnal IG was 1.13 versus $1.30 \mathrm{mmol} / \mathrm{L}$ with IDegAsp and IGlar. ${ }^{76}$ Nocturnal rates of high IG episodes were 48\% lower with IDegAsp, while the rates of nocturnal low interstitial glucose levels did not differ between groups. ${ }^{76}$ As expected, IDegAsp was associated with reduced postdinner IG excursions (IDegAsp/ IGlar, $-1.42 \mathrm{mmol} / \mathrm{L}[-2.15,-0.70] \mathrm{mmol} / \mathrm{L})$.

In summary, the administration at dinner of IDegAsp in type 2 diabetic patients can provide better postdinner PG levels, less nocturnal PG variability at a rate of nocturnal hypoglycemia that is low and comparable to that observed with IGlar.

In the second Phase II, open-label, three-arm, parallel group, randomized, controlled, 16-week, treat-to-target trial, the efficacy and safety of IDegAsp have been compared with biphasic IAsp 30 (BIAsp 30, 30\% v/v soluble IAsp and $70 \% \mathrm{v} / \mathrm{v}$ protamine-crystallized IAsp), both given twice daily in combination with metformin, in insulin-naïve subjects with type 2 diabetes inadequately controlled with oral antidiabetic drugs. ${ }^{75}$ Insulin-naïve subjects have been randomized to twice-daily IDegAsp, alternative IDegAsp formulation (containing 45\% IAsp) or BIAsp 30 - all in combination with metformin. As for the study by Heise, ${ }^{74}$ the results for IDegAsp 55:45 are not discussed here. The 
Table 3 Summary of main studies using IDeg/IAsp in patients with type I and type 2 DM

\begin{tabular}{|c|c|c|c|c|c|c|}
\hline Authors & Study design & Comparators & $\mathrm{HbA}_{\mathrm{Ic}}$ change \% & Hypo (PYE) & $\begin{array}{l}\text { Nocturnal } \\
\text { hypo (PYE) }\end{array}$ & $\begin{array}{l}\text { Type of DM } \\
\text { (number of } \\
\text { patients) }\end{array}$ \\
\hline $\begin{array}{l}\text { Hirsch IB et } \mathrm{al}^{20} \\
\text { Diabetes Care, } \\
2012\end{array}$ & $\begin{array}{l}\text { 26-week, multinational, } \\
\text { multicenter, open-label, two- } \\
\text { arm, parallel, randomized, } \\
\text { treat-to-target trial }\end{array}$ & $\begin{array}{l}\text { IDegAsp versus } \\
\text { IDet }\end{array}$ & $\begin{array}{l}\text { IDegAsp, }-0.75 \text {; } \\
\text { IDet, }-0.70\end{array}$ & $\begin{array}{l}\text { IDegAsp, } 39.17 \text {; } \\
\text { IDet, } 44.34\end{array}$ & $\begin{array}{l}\text { IDegAsp, 3.7I; } \\
\text { IDet, 5.72; } \\
(P<0.05)\end{array}$ & $\begin{array}{l}\text { TIDM } \\
(n=548)\end{array}$ \\
\hline $\begin{array}{l}\text { Heise } T \text { et } \mathrm{al}^{74} \\
\text { Diabetes Care, } \\
201 \mathrm{I}\end{array}$ & $\begin{array}{l}\text { Phase II, open-label, } \\
\text { randomized, controlled, } \\
\text { I6-week trial }\end{array}$ & $\begin{array}{l}\text { IDegAsp versus } \\
\text { IGlar }\end{array}$ & $\begin{array}{l}\text { IDegAsp, -I.3; } \\
\text { IGlar, -I.3 }\end{array}$ & $\begin{array}{l}\text { IDegAsp, I.2; } \\
\text { IGlar, } 0.7\end{array}$ & $\begin{array}{l}\text { IDegAsp, I; } \\
\text { IGlar, } 3\end{array}$ & $\begin{array}{l}\text { T2DM } \\
(n=\mid 19)\end{array}$ \\
\hline $\begin{array}{l}\text { Niskanen } L \text { et } \mathrm{a}^{75} \\
\text { Eur J Endocrinol, } \\
2012\end{array}$ & $\begin{array}{l}\text { Phase II, open-label, three-arm, } \\
\text { parallel-group, randomized, } \\
\text { controlled, I6-week trial }\end{array}$ & $\begin{array}{l}\text { IDegAsp versus } \\
\text { BIAsp } 30\end{array}$ & $\begin{array}{l}\text { IDegAsp, -I.8; } \\
\text { BIAsp, -I.8 }\end{array}$ & $\begin{array}{l}\text { IDegAsp, 2.9; } \\
\text { BiAsp 30, } 7.3\end{array}$ & $\begin{array}{l}\text { IDegAsp, 0.4; } \\
\text { BIAsp 30, I.I }\end{array}$ & $\begin{array}{l}\text { T2DM } \\
(n=122)\end{array}$ \\
\hline $\begin{array}{l}\text { Onishi } Y \text { et al } \\
\text { Diabetes Obes } \\
\text { Metab, } 2013\end{array}$ & $\begin{array}{l}\text { Phase III, 26-week, open-label, } \\
\text { randomized, stratified, parallel- } \\
\text { group, multicenter, treat-to- } \\
\text { target trial }\end{array}$ & $\begin{array}{l}\text { IDegAsp versus } \\
\text { Iglar }\end{array}$ & $\begin{array}{l}\text { IDegAsp, }- \text { I.4; } \\
\text { IGlar, }- \text { I.2; } \\
(P<0.0 \text { I })\end{array}$ & $\begin{array}{l}\text { IDegAsp, I.9I; } \\
\text { IGlar, 2.7I }\end{array}$ & $\begin{array}{l}\text { IDegAsp, 0.39; } \\
\text { IGlar, } 0.53\end{array}$ & $\begin{array}{l}\text { T2DM } \\
(n=296)\end{array}$ \\
\hline
\end{tabular}

Abbreviations: IDegAsp, insulin degludec/insulin aspart; IDet, insulin detemir; DM, diabetes mellitus; IGlar, insulin glargine; BIAsp 30, biphasic insulin aspart 30; hypo, hypoglycemia; PYE, episodes per patient/years of exposure; TIDM, type I diabetes mellitus; T2DM, type 2 diabetes mellitus; $\mathrm{HbA}_{\mathrm{Ic}}$, glycated hemoglobin.

starting insulin dose was six units before breakfast and dinner (main evening meal). The breakfast dose was adjusted on the basis of predinner self-measured PG values, while the dinner dose was adjusted according to the prebreakfast selfmeasured PG values, aiming at a PG level of 4.0-6.0 mmol/L. The primary endpoint was change in $\mathrm{HbA}_{1 \mathrm{c}}$ after 16 weeks of treatment compared with baseline.

After 16 weeks of treatment, mean reductions in $\mathrm{HbA}_{1 \mathrm{c}}$ were comparable for both treatment groups $(6.7 \%$ for both IDegAsp and BIAsp 30). With IDegAsp, a significantly higher proportion of patients $(67 \%)$ achieved $\mathrm{HbA}_{1 \mathrm{c}} 7.0 \%$ in the absence of confirmed hypoglycemia in the last 4 weeks of treatment, as compared with BIAsp 30 (40\%). Mean fasting PG values were significantly lower for IDegAsp versus BIAsp 30 (treatment difference, $-0.99 \mathrm{mmol} / \mathrm{L}$ [95\% CI - 1.68; -0.29]). Moreover, IDegAsp was associated with a significantly lower rate of confirmed hypoglycemia (58\%) versus BIAsp 30 (RR: 0.42, 95\% CI: [0.23; 0.75]). Finally, IDegAsp had numerically lower rates of nocturnal confirmed hypoglycemia as compared to BIAsp 30 (0.4 versus 1.1 episodes/ patient year; RR: 0.33, 95\% CI: [0.09; 1.14]). These results show that IDegAsp provided comparable overall glycemic control to BIAsp 30, but with a significantly lower rate of hypoglycemia.

More recently, the efficacy and safety of IDegAsp have been investigated in a (confirmatory) Phase III, 26-week, open-label, treat-to-target trial, which recruited 296 Japanese insulin-naïve type 2 diabetic subjects, inadequately controlled with oral antidiabetic drugs alone, randomized to once-daily injections of IDegAsp or IGlar. ${ }^{77}$ After 26 weeks, mean $\mathrm{HbA}_{1 \mathrm{c}}$ was 7\% with IDegAsp and 7.3\% with IGlar. The estimated treatment difference (ETD) for IDegAsp/IGlar was $-0.28 \%$ points; 95\% CI $[-0.46 ;-0.10] ; P<0.01$. This demonstrates the superiority of IDegAsp as compared to IGlar in terms of lowering $\mathrm{HbA}_{1 \mathrm{c}}{ }^{77}$ At end-of-trial, the mean FPG was similar between the two treatments, not significantly different for IDegAsp and IGlar (5.7 versus $5.6 \mathrm{mmol} / \mathrm{L})$. The ETD was IDegAsp/IGlar, $0.15 \mathrm{mmol} / \mathrm{L}$ [-0.29; 0.60] (95\% CI). ${ }^{77}$

Noteworthy, the estimated rate of confirmed hypoglycemia was lower by $27 \%$ with IDegAsp than it was with IGlar. Similarly, the estimated rate of nocturnal confirmed hypoglycemia was lower in IDegAsp-treated patients by $25 \%$ although the difference was not statistically significant in both cases. Regarding other safety results, the mean daily insulin doses, increase in body weight, and adverse event profiles were similar between the groups. ${ }^{77}$ Overall, these results show, in a specific ethnic group, the superiority of IDegAsp versus IGlar in providing good glycemic control. Therefore, IDegAsp, in special settings, may represent a real alternative treatment option and not just another insulin.

The main studies using IDeg/IAsp in patients with type 1 and type $2 \mathrm{DM}$ are summarized in Table 3.

\section{Conclusion}

Good glycemic control remains the basis of managing DM and treating to target is the crucial goal to prevent and/or delay the onset of diabetic complications in patients with type 1 or type 2 diabetes. $^{2}$ Determinants for achieving glycemic control are complex, and the reasons for poor glycemic control in diabetes are multifaceted. Intensive glucose therapy is 
associated with a higher risk of hypoglycemia that, in turn, has been related to recurrent (cardiovascular) morbidity and an increased risk of emergency room visits and hospitalization. A history of hypoglycemia and the fear of further episodes, particularly at night, continue to be the main barriers to optimizing insulin therapy. The burden of multiple daily insulin injections also emerges as a key obstacle to intensifying therapy and/or adhering to it. ${ }^{15-19}$ Therefore, overcoming these barriers assumes greater priority in the treatment of diabetes. Although the introduction of the insulin analogs has offered new opportunities ${ }^{22,23}$ in terms of pharmacokinetics and pharmacodynamics, currently available insulin analogs still have some limitations..$^{30,31}$

The new combination IDeg/IAsp (IDegAsp), formulated with ultra-long-acting IDeg and rapid-acting IAsp, with no molecular interactions between the two analogs, provides - in a single injection - specific meal coverage with full 24-hour basal coverage. Results from the clinical trials show that IDegAsp could be a promising treatment option in both type 1 and type 2 DM.

In type 1 diabetes, IDegAsp has shown to provide similar, noninferior glycemic control to a standard basal bolus regimen, with additional benefits of significantly lower episodes of hypoglycemia (particularly nocturnal) and fewer daily insulin injections. The complexity of some insulin regimens with multiple daily injections can induce some patients to regularly omit insulin. Conversely, a more flexible regime provided by IDegAsp can improve satisfaction with insulin regimen and the reliability of insulin use. However, a possible limit of IDegAsp is the difficulty to make day-to-day dose adjustment; so, type 1 patients could not be the target group for IDegAsp. Nevertheless, for special patients, with physical or intellectual limitations, who would not consider self-adjusting their insulin doses, the use of IDegAsp may be quite convenient.

Although various viewpoints exist regarding whether insulin treatment should be started in type 2 diabetes and a variety of strategies for initiating and titrating insulin therapy are currently used, insulin therapy is strongly recommended in type 2 diabetic patients inadequately controlled on maximal doses of conventional oral agents. ${ }^{2}$

Results of clinical trials concerning the use of IDegAsp show that the new formulation may be an appropriate and reasonable option for initiating insulin therapy in type 2 diabetes. Indeed, in type 2 diabetic patients, IDegAsp provides comparable overall glycemic control to IGlar or BIAsp 30 , with similar low rates of hypoglycemia, as compared with IGlar, while the difference becomes significant with respect to BIAsp 30. An additional advantage of IDegAsp is the ability to target postprandial glucose (PPG). In this regard, several collections of direct and indirect evidence suggest that PPG is independently related to cardiovascular disease and support the idea that PPG should be assessed and that glucose excursions with meals should be controlled. ${ }^{78}$

Therefore, the effectiveness of IDegAsp in controlling PPG would be clinically relevant and should be considered also in the perspective to delay progression to a full basal-bolus insulin replacement therapy. Based on the results of meta-analyses, the European Union licensed the IDeg and IDeg/IAsp combination, without any concern about cardiovascular safety.

In conclusion, IDegAsp may be a reasonable treatment choice in the wide range of treatment options (especially for type 2 diabetes). However, definitive conclusions on the real innovation and clinical impact of IDegAsp have to be withheld, due to the fact that available data are still limited and trials have an open-label design and are of relatively short duration. Moreover, the assessment of cost-effectiveness will require more detailed analysis. Therefore, more information has to be gathered to allow critical analysis of true placement of IDegAsp in the treatment algorithm of diabetes.

\section{Disclosure}

Stefano Del Prato has received honoraria for advisory work and lectures from AstraZeneca, Boehringer Ingelheim, Bristol-Myers Squibb, Eli Lilly, GlaxoSmithKline, Intarcia, Janssen, Merck Sharpe and Dohme, Novartis, Novo Nordisk, Roche Diagnostics, Sanofi-Aventis, and Takeda; and research support from Bristol-Myers Squibb, Merck Sharpe and Dohme, Novartis, and Novo Nordisk. Angela Dardano, Cristina Bianchi and Roberto Miccoli have no conflict of interest to declare.

\section{References}

1. Whiting DR, Guariguata L, Weil C, Shaw J. IDF diabetes atlas: global estimates of the prevalence of diabetes for 2011 and 2030. Diabetes Res Clin Pract. 2011;94(3):311-321.

2. Inzucchi SE, Bergenstal RM, Buse JB, et al; American Diabetes Association (ADA); European Association for the Study of Diabetes (EASD). Management of hyperglycemia in type 2 diabetes: a patient-centered approach: position statement of the American Diabetes Association (ADA) and the European Association for the Study of Diabetes (EASD). Diabetes Care. 2012;35(6):1364-1379.

3. Reichard P, Nilsson BY, Rosenqvist U. The effect of long-term intensified insulin treatment on the development of microvascular complications of diabetes mellitus. N Engl J Med. 1993;329(5):304-309.

4. [No authors listed] Intensive blood-glucose control with sulphonylureas or insulin compared with conventional treatment and risk of complications in patients with type 2 diabetes (UKPDS 33). UK Prospective Diabetes Study (UKPDS) Group. Lancet. 1998;352(9131):837-853.

5. [No authors listed] Effect of intensive blood-glucose control with metformin on complications in overweight patients with type 2 diabetes (UKPDS 34). UK Prospective Diabetes Study (UKPDS) Group. Lancet. 1998;352(9131):854-865. 
6. [No authors listed] Retinopathy and nephropathy in patients with type 1 diabetes four years after a trial of intensive therapy. The Diabetes Control and Complications Trial/Epidemiology of Diabetes Interventions and Complications Research Group. N Engl J Med. 2000;342(6):381-389.

7. Bailey CJ, Blonde L, Del Prato S, Leiter LA, Nesto R; Global Partnership for Effective Diabetes Management. What are the practical implications for treating diabetes in light of recent evidence? Updated recommendations from the Global Partnership for Effective Diabetes Management. Diab Vasc Dis Res. 2009;6(4):283-287.

8. Ray KK, Seshasai SR, Wijesuriya S, et al. Effect of intensive control of glucose on cardiovascular outcomes and death in patients with diabetes mellitus: a meta-analysis of randomised controlled trials. Lancet. 2009;373(9677):1765-1772.

9. Yakubovich N, Gerstein HC. Serious cardiovascular outcomes in diabetes: the role of hypoglycemia. Circulation. 2011;123(3):342-348.

10. Nathan DM, Cleary PA, Backlund JY, et al; Diabetes Control and Complications Trial/Epidemiology of Diabetes Interventions and Complications (DCCT/EDIC) Study Research Group. Intensive diabetes treatment and cardiovascular disease in patients with type 1 diabetes. N Engl J Med. 2005;353(25):2643-2653.

11. Skyler JS, Bergenstal R, Bonow RO, et al; American Diabetes Association; American College of Cardiology Foundation; American Heart Association. Intensive glycemic control and the prevention of cardiovascular events: implications of the ACCORD, ADVANCE, and VA diabetes trials: a position statement of the American Diabetes Association and a scientific statement of the American College of Cardiology Foundation and the American Heart Association. Diabetes Care. 2009;32(1):187-192.

12. Skyler JS, Bergenstal R, Bonow RO, et al; American Diabetes Association; American College of Cardiology Foundation; American Heart Association. Intensive glycemic control and the prevention of cardiovascular events: implications of the ACCORD, ADVANCE, and VA diabetes trials: a position statement of the American Diabetes Association and a scientific statement of the American College of Cardiology Foundation and the American Heart Association. Circulation. 2009;119(2):351-357.

13. Kong AP, Yang X, Luk A, et al. Severe hypoglycemia identifies vulnerable patients with type 2 diabetes at risk for premature death and all-site cancer: the Hong Kong diabetes registry. Diabetes Care. 2014;37(4):1024-1031.

14. Budnitz DS, Lovegrove MC, Shehab N, Richards CL. Emergency hospitalizations for adverse drug events in older Americans. $N$ Engl J Med. 2011;365(21):2002-2012.

15. Holstein A, Egberts EH. Risk of hypoglycaemia with oral antidiabetic agents in patients with Type 2 diabetes. Exp Clin Endocrinol Diabetes. 2003;111(7):405-414.

16. Leese GP, Wang J, Broomhall J, et al; DARTS/MEMO Collaboration. Frequency of severe hypoglycemia requiring emergency treatment in type 1 and type 2 diabetes: a population-based study of health service resource use. Diabetes Care. 2003;26(4):1176-1180.

17. Bulsara MK, Holman CD, Davis EA, Jones TW. The impact of a decade of changing treatment on rates of severe hypoglycemia in a population-based cohort of children with type 1 diabetes. Diabetes Care. 2004;27(10):2293-2298.

18. Evans M, Khunti K, Mamdani M, et al. Health-related quality of life associated with daytime and nocturnal hypoglycaemic events: a time trade-off survey in five countries. Health Qual Life Outcomes. 2013;11:90.

19. Peyrot M, Barnett AH, Meneghini LF, Schumm-Draeger PM. Insulin adherence behaviours and barriers in the multinational Global Attitudes of Patients and Physicians in Insulin Therapy study. Diabet Med. 2012;29(5):682-689.

20. Hirsch IB, Bode B, Courreges JP, et al. Insulin degludec/insulin aspart administered once daily at any meal, with insulin aspart at other meals versus a standard basal-bolus regimen in patients with type 1 diabetes: a 26-week, phase 3, randomized, open-label, treat-to-target trial. Diabetes Care. 2012;35(11):2174-2181.
21. Bolli GB, Di Marchi RD, Park GD, Pramming S, Koivisto VA. Insulin analogues and their potential in the management of diabetes mellitus. Diabetologia. 1999;42(10):1151-1167.

22. Hirsch IB. Insulin analogues. N Engl J Med. 2005;352(2):174-183.

23. Crasto W, Jarvis J, Khunti K, Davies MJ. New insulins and new insulin regimens: a review of their role in improving glycaemic control in patients with diabetes. Postgrad Med J. 2009;85(1003):257-267.

24. DeWitt DE, Hirsch IB. Outpatient insulin therapy in type 1 and type 2 diabetes mellitus: scientific review. JAMA. 2003;289(17):2254-2264.

25. Rosenstock J, Dailey G, Massi-Benedetti M, Fritsche A, Lin Z, Salzman A Reduced hypoglycemia risk with insulin glargine: a meta-analysis comparing insulin glargine with human NPH insulin in type 2 diabetes. Diabetes Care. 2005;28(4):950-955.

26. Gough SC. A review of human and analogue insulin trials. Diabetes Res Clin Pract. 2007;77(1):1-15.

27. Becker RH, Frick AD. Clinical pharmacokinetics and pharmacodynamics of insulin glulisine. Clin Pharmacokinet. 2008;47(1):7-20.

28. Hartman I. Insulin analogs: impact on treatment success, satisfaction, quality of life, and adherence. Clin Med Res. 2008;6(2):54-67.

29. Owens DR, Bolli GB. Beyond the era of NPH insulin - long-acting insulin analogs: chemistry, comparative pharmacology, and clinical application. Diabetes Technol Ther. 2008;10(5):333-349.

30. Evans M, Schumm-Draeger PM, Vora J, King AB. A review of modern insulin analogue pharmacokinetic and pharmacodynamic profiles in type 2 diabetes: improvements and limitations. Diabetes Obes Metab. 2011;13(8):677-684.

31. Tibaldi JM. Evolution of insulin development: focus on key parameters. Adv Ther. 2012;29(7):590-619.

32. Kalra S, Baruah MP, Niazi AK. Degludec: a novel basal insulin. Recent Pat Endocr Metab Immune Drug Discov. 2012;6(1):18-23.

33. European Medicines Agency. Tresiba (insulin degludec): EU summary of product characteristics; 2013. Available from: http:/www.ema. europa.eu/docs/en_GB/document_library/EPAR_-Product_Information/human/002498/WC500138940.pdf. Accessed February 1, 2013.

34. Jonassen I, Havelund S, Hoeg-Jensen T, Steensgaard DB, Wahlund PO, Ribel U. Design of the novel protraction mechanism of insulin degludec, an ultra-long-acting basal insulin. Pharm Res. 2012;29(8):2104-2114.

35. Heise T, Hermanski L, Nosek L, Feldman A, Rasmussen S, Haahr H. Insulin degludec: four times lower pharmacodynamic variability than insulin glargine under steady-state conditions in type 1 diabetes. Diabetes Obes Metab. 2012;14(9):859-864.

36. Wang F, Surh J, Kaur M. Insulin degludec as an ultralong-acting basal insulin once a day: a systematic review. Diabetes Metab Syndr Obes. 2012;5:191-204.

37. Goldman-Levine JD, Patel DK, Schnee DM. Insulin degludec: a novel basal insulin analogue. Ann Pharmacother. 2013;47(2):269-277.

38. Keating GM. Insulin degludec and insulin degludec/insulin aspart: a review of their use in the management of diabetes mellitus. Drugs. 2013;73(6):575-593.

39. Gough SC, Harris S, Woo V, Davies M. Insulin degludec: overview of a novel ultra long-acting basal insulin. Diabetes Obes Metab. 2013;15(4): 301-309.

40. Birkeland KI, Home PD, Wendisch U, et al. Insulin degludec in type 1 diabetes: a randomized controlled trial of a new-generation ultra-long-acting insulin compared with insulin glargine. Diabetes Care. 2011;34(3):661-665.

41. Heller S, Buse J, Fisher M, et al; BEGIN Basal-Bolus Type 1 Trial Investigators. Insulin degludec, an ultra-longacting basal insulin, versus insulin glargine in basal-bolus treatment with mealtime insulin aspart in type 1 diabetes (BEGIN Basal-Bolus Type 1): a phase 3, randomised, open-label, treat-to-target non-inferiority trial. Lancet. 2012;379(9825):1489-1497.

42. Mathieu C, Hollander P, Miranda-Palma B, et al; NN1250-3770 (BEGIN: Flex T1) Trial Investigators. Efficacy and safety of insulin degludec in a flexible dosing regimen vs insulin glargine in patients with type 1 diabetes (BEGIN: Flex T1): a 26-week randomized, treatto-target trial with a 26-week extension. J Clin Endocrinol Metab. 2013;98(3):1154-1162. 
43. Bode BW, Buse JB, Fisher M, et al; BEGIN ${ }^{\circledR}$ Basal-Bolus Type 1 trial investigators. Insulin degludec improves glycaemic control with lower nocturnal hypoglycaemia risk than insulin glargine in basal-bolus treatment with mealtime insulin aspart in Type 1 diabetes (BEGIN $\left({ }^{\circledR}\right)$ Basal-Bolus Type 1): 2-year results of a randomized clinical trial. Diabet Med. 2013;30(11):1293-1297.

44. Koehler G, Heller S, Korsatko S, et al. Insulin degludec is not associated with a delayed or diminished response to hypoglycaemia compared with insulin glargine in type 1 diabetes: a double-blind randomised crossover study. Diabetologia. 2014;57(1):40-49.

45. Korsatko S, Deller S, Mader JK, et al. Ultra-long pharmacokinetic properties of insulin degludec are comparable in elderly subjects and younger adults with type 1 diabetes mellitus. Drugs Aging. 2014;31(1): 47-53.

46. Biester T, Blaesig S, Remus K, et al. Insulin degludec's ultra-long pharmacokinetic properties observed in adults are retained in children and adolescents with type 1 diabetes. Pediatr Diabetes. 2014; 15(1):27-33.

47. Davies MJ, Gross JL, Ono Y, et al; on behalf of the BEGIN BB T1 study group. Efficacy and safety of insulin degludec given as part of basal-bolus treatment with mealtime insulin aspart in type 1 diabetes: a 26-week randomized, open-label, treat-to-target non-inferiority trial. Diabetes Obes Metab. Epub 2014 Apr 7.

48. Zinman B, Fulcher G, Rao PV, et al. Insulin degludec, an ultra-longacting basal insulin, once a day or three times a week versus insulin glargine once a day in patients with type 2 diabetes: a 16-week, randomised, open-label, phase 2 trial. Lancet. 2011;377(9769): 924-931.

49. Garber AJ, King AB, Del Prato S, et al; NN1250-3582 (BEGIN BB T2D) Trial Investigators. Insulin degludec, an ultra-longacting basal insulin, versus insulin glargine in basal-bolus treatment with mealtime insulin aspart in type 2 diabetes (BEGIN Basal-Bolus Type 2): a phase 3, randomised, open-label, treat-to-target non-inferiority trial. Lancet. 2012;379(9825):1498-1507.

50. Heise T, Nosek L, Bøttcher SG, Hastrup H, Haahr H. Ultra-long-acting insulin degludec has a flat and stable glucose-lowering effect in type 2 diabetes. Diabetes Obes Metab. 2012;14(10):944-950.

51. Zinman B, Philis-Tsimikas A, Cariou B, et al; NN1250-3579 (BEGIN Once Long) Trial Investigators. Insulin degludec versus insulin glargine in insulin-naive patients with type 2 diabetes: a 1-year, randomized, treat-to-target trial (BEGIN Once Long). Diabetes Care. 2012;35(12):2464-2471.

52. Meneghini L, Atkin SL, Gough SC, et al; NN1250-3668 (BEGIN FLEX) Trial Investigators. The efficacy and safety of insulin degludec given in variable once-daily dosing intervals compared with insulin glargine and insulin degludec dosed at the same time daily: a 26-week, randomized, open-label, parallel-group, treat-to-target trial in individuals with type 2 diabetes. Diabetes Care. 2013;36(4):858-864.

53. Philis-Tsimikas A, Del Prato S, Satman I, et al. Effect of insulin degludec versus sitagliptin in patients with type 2 diabetes uncontrolled on oral antidiabetic agents. Diabetes Obes Metab. 2013;15(8): 760-766.

54. Gough SC, Bhargava A, Jain R, Mersebach H, Rasmussen S, Bergenstal RM. Low-volume insulin degludec 200 units/ml once daily improves glycemic control similarly to insulin glargine with a low risk of hypoglycemia in insulin-naive patients with type 2 diabetes: a 26-week, randomized, controlled, multinational, treat-to-target trial: the BEGIN LOW VOLUME trial. Diabetes Care. 2013;36(9): 2536-2542.

55. Philis-Tsimikas A, Brod M, Niemeyer M, Ocampo Francisco AM, Rothman J. Insulin degludec once-daily in type 2 diabetes: simple or step-wise titration (BEGIN: once simple use). Adv Ther. 2013;30(6):607-622.

56. Rodbard HW, Cariou B, Zinman B, et al; BEGIN Once Long trial investigators. Comparison of insulin degludec with insulin glargine in insulin-naive subjects with Type 2 diabetes: a 2-year randomized, treat-to-target trial. Diabet Med. 2013;30(11):1298-1304.
57. Zinman B, DeVries JH, Bode B, et al; NN1250-3724 (BEGIN:EASY AM) and NN1250-3718 (BEGIN:EASY PM) Trial Investigators. Efficacy and safety of insulin degludec three times a week versus insulin glargine once a day in insulin-naive patients with type 2 diabetes: results of two phase 3, 26 week, randomised, open-label, treat-to-target, noninferiority trials. Lancet Diabetes Endocrinol. 2013;1(2):123-131.

58. Kiss I, Arold G, Roepstorff C, Bøttcher SG, Klim S, Haahr H. Insulin degludec: pharmacokinetics in patients with renal impairment. Clin Pharmacokinet. 2014;53(2):175-183.

59. Kupčová V, Arold G, Roepstorff C, Højbjerre M, Klim S, Haahr H. Insulin degludec: pharmacokinetic properties in subjects with hepatic impairment. Clin Drug Investig. 2014;34(2):127-133.

60. Mathieu C, Rodbard HW, Cariou B, et al; on behalf of the BEGIN: VICTOZA ADD-ON (NN1250-3948) study group. A comparison of adding liraglutide versus a single daily dose of insulin aspart to insulin degludec in subjects with type 2 diabetes (BEGIN: VICTOZA ADD-ON). Diabetes Obes Metab. Epub January 20, 2014.

61. Rodbard HW, Cariou B, Zinman B, et al. Health status and hypoglycaemia with insulin degludec versus insulin glargine: a 2-year trial in insulin-naïve patients with type 2 diabetes. Diabetes Obes Metab. Epub February 4, 2014.

62. Hompesch M, Morrow L, Watkins E, Roepstorff C, Thomsen HF, $\mathrm{Haahr} \mathrm{H}$. Pharmacokinetic and pharmacodynamic responses of insulin degludec in African American, white, and Hispanic/Latino patients with type 2 diabetes mellitus. Clin Ther. 2014;36(4):507-515.

63. Bode BW, Chaykin LB, Sussman AM, et al. Efficacy and Safety of Insulin Degludec 200 U/ML and Insulin Degludec 100 U/ML in Patients with Type 2 Diabetes (Begin: Compare). Endocr Pract. Epub February 11, 2014:1-16.

64. European Medicines Agency. Ryzodeg (insulin degludec/insulin aspart): EU summary of product characteristics; 2013. Available from: http:// www.ema.europa.eu/docs/en_GB/document_library/EPAR_-Product_ Information/human/002499/WC500139011.pdf. Accessed February 1, 2013.

65. Ma Z, Parkner T, Christiansen JS, Laursen T. IDegAsp: a novel soluble insulin analogs combination. Expert Opin Biol Ther. 2012;12(11): $1533-1540$.

66. Heller S, Kurtzhals P, Verge D, Lindholm A. Insulin aspart: promising early results borne out in clinical practice. Expert Opin Pharmacother. 2002;3(2):183-195.

67. Østerberg O, Erichsen L, Ingwersen SH, Plum A, Poulsen HE, Vicini P. Pharmacokinetic and pharmacodynamic properties of insulin aspart and human insulin. J Pharmacokinet Pharmacodyn. 2003;30(3): 221-235.

68. Home PD. The pharmacokinetics and pharmacodynamics of rapidacting insulin analogues and their clinical consequences. Diabetes Obes Metab. 2012;14(9):780-788.

69. Reynolds NA, Wagstaff AJ. Insulin aspart: a review of its use in the management of type 1 or 2 diabetes mellitus. Drugs. 2004;64(17): 1957-1974.

70. Heller S, McCance DR, Moghissi E, Nazeri A, Kordonouri O. Diversity in diabetes: the role of insulin aspart. Diabetes Metab Res Rev. 2012;28(1):50-61.

71. Rendell M. Insulin degludec: a long-acting modern insulin analogue with a predictable pharmacokinetic/pharmacodynamic profile. Drugs Today (Barc). 2013;49(6):387-397.

72. Poon K, King AB. Glargine and detemir: Safety and efficacy profiles of the long-acting basal insulin analogs. Drug Healthc Patient Saf. 2010;2:213-223.

73. European Medicines Agency. EPAR summary for the public: Ryzodeg (insulin degludec/insulin aspart). Available from: http://www.ema. europa.eu/docs/en_GB/document_library/EPAR_-_Summary_for_the public/human/002499/WC500139014.pdf. Accessed July 1, 2014.

74. Heise T, Tack CJ, Cuddihy R, et al. A new-generation ultra-long-acting basal insulin with a bolus boost compared with insulin glargine in insulin-naive people with type 2 diabetes: a randomized, controlled trial. Diabetes Care. 2011;34(3):669-674. 
75. Niskanen L, Leiter LA, Franek E, et al. Comparison of a soluble co-formulation of insulin degludec/insulin aspart vs biphasic insulin aspart 30 in type 2 diabetes: a randomised trial. Eur J Endocrinol. 2012;167(2):287-294.

76. Liebl A, Davidson J, Mersebach H, Dykiel P, Tack CJ, Heise T. A novel insulin combination of insulin degludec and insulin aspart achieves a more stable overnight glucose profile than insulin glargine: results from continuous glucose monitoring in a proof-of-concept trial. J Diabetes Sci Technol. 2013;7(5):1328-1336.
77. Onishi Y, Ono Y, Rabøl R, Endahl L, Nakamura S. Superior glycaemic control with once-daily insulin degludec/insulin aspart versus insulin glargine in Japanese adults with type 2 diabetes inadequately controlled with oral drugs: a randomized, controlled phase 3 trial. Diabetes Obes Metab. 2013;15(9):826-832.

78. Bonora E. Postprandial peaks as a risk factor for cardiovascular disease: epidemiological perspectives. Int J Clin Pract Suppl. 2002;129:5-11.

\section{Publish your work in this journal}

Vascular Health and Risk Management is an international, peerreviewed journal of therapeutics and risk management, focusing on concise rapid reporting of clinical studies on the processes involved in the maintenance of vascular health; the monitoring, prevention and treatment of vascular disease and its sequelae; and the involvement of metabolic disorders, particularly diabetes. This journal is indexed on PubMed Central and MedLine. The manuscript management system is completely online and includes a very quick and fair peer-review system, which is all easy to use. Visit http://www.dovepress.com/ testimonials.php to read real quotes from published authors.

Submit your manuscript here: http://www.dovepress.com/vascular-health-and-risk-management-journal 